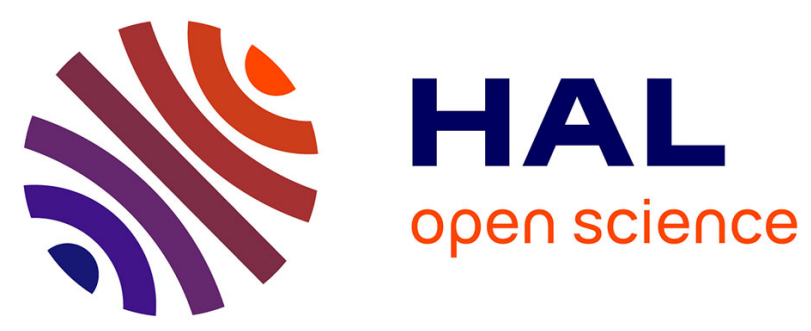

\title{
CONTROLLED ZnO DEPOSITS FOR GAS SENSORS
}

Pamela Yoboué, Paul Kouakou, Aladji Kamagaté, Philippe Menini, Fabien

Mesnilgrente, Véronique Conédéra, Norbert Fabre

\section{To cite this version:}

Pamela Yoboué, Paul Kouakou, Aladji Kamagaté, Philippe Menini, Fabien Mesnilgrente, et al.. CONTROLLED ZnO DEPOSITS FOR GAS SENSORS. International Journal of Materials Engineering and Technology, 2019, 18 (2), pp.55-66. 10.17654/MT018020055 . hal-02537202

\section{HAL Id: hal-02537202 \\ https://hal.laas.fr/hal-02537202}

Submitted on 15 Apr 2020

HAL is a multi-disciplinary open access archive for the deposit and dissemination of scientific research documents, whether they are published or not. The documents may come from teaching and research institutions in France or abroad, or from public or private research centers.
L'archive ouverte pluridisciplinaire HAL, est destinée au dépôt et à la diffusion de documents scientifiques de niveau recherche, publiés ou non, émanant des établissements d'enseignement et de recherche français ou étrangers, des laboratoires publics ou privés. 


\title{
CONTROLLED ZnO DEPOSITS FOR GAS SENSORS
}

\author{
Pamela Yoboué $^{1}$, Paul Kouakou ${ }^{2}$, Aladji Kamagaté ${ }^{1}$, Philippe Ménini ${ }^{3,4}$, \\ Fabien Mesnilgrente ${ }^{3,4}$, Véronique Conedera ${ }^{3,4}$ and Norbert Fabre ${ }^{3,4}$ \\ ${ }^{1}$ Ecole Supérieure Africaine des Technologies \\ de l'Information et de la Communication \\ Abidjan, Côte d'Ivoire \\ ${ }^{2}$ Laboratory of Fundamental Physics and Applications \\ Nangui Abrogoua University \\ 02 BP 801 Abidjan 02, Côte d'Ivoire
}

${ }^{3}$ LAAS-CNRS

7 avenue du colonel Roche - Toulouse

France

${ }^{4}$ Université de Toulouse

UPS, INP, INSA, ISAE

Toulouse, France

\begin{abstract}
Zinc oxide $(\mathrm{ZnO})$ is widely used for its capability to detect gases. There are several known methods to synthetize and deposit $\mathrm{ZnO}$ for gas sensor applications. We have developed a new process based on $\mathrm{ZnO}$ nanoparticles from Sigma Aldrich manufacturer deposited by an inkjet technique. The process achieved is based on stable $\mathrm{ZnO}$ nanoparticles ink obtained by mixing $10 \%$ weight of commercial powder with diethylene glycol (DEG). This ink has been deposited on
\end{abstract}


a microhotplate that can operate up to $550^{\circ} \mathrm{C}$ with a low power of consumption (less than $60 \mathrm{~mW}$ ).

The gas tests presented in this article show good results concerning the sensor response and its stability in the presence of gases.

\section{Introduction}

Metal oxides have been widely used in numerous applications due to their low cost, flexibility and numerous applications [1-4]. In the field of gas detection, the operating principle is widely described in literature [5-8]. It consists in a change of metal oxide's resistance value due to semiconducting behavior affected by gas adsorption. The sensitivity of the sensor to a gas depends on this resistance.

Several studies have been carried out on improving the sensitivity of metal oxides in order to control indoor air. But few metal oxides sensors are currently on the market while this technology has a strong potential to produce miniaturized sensors at very low cost.

The realization of a sensor based on metal oxides for the detection of indoor pollutant gases would therefore be an opportunity to upset the market and a good alternative to electrochemical and infrared sensors due to its high performance in terms of detection sensitivity and stability over time.

Indeed, it has been proven that the sensitivity of the sensor to a gas is greatly improved not only with the reduction of the size of the nanoparticles around the Debye length, but also by controlling the profile of the deposit without cracks, dislocations and phenomenon known as "coffee staining effect" [8-13].

In this work, we were interested in zinc oxide $(\mathrm{ZnO})$ as sensing element. Indeed, this material is used for its various characteristics such as photoresistivity, piezoelectricity and also for its capability for gas detection.

There are several methods used to deposit $\mathrm{ZnO}$ sensitive layer as well as standard PVD methods [14, 15], CVD process [16, 17] including inkjet printing method [18]. Those methods can be expensive. Moreover, 
sometimes when the surface contact angle is lower, particles are distributed at the periphery of the device during the drying phase well-known as "coffee staining effect" [12].

To achieve a more controlled and homogeneous particles distribution, an innovative method of deposit of $\mathrm{ZnO}$ nanoparticles by inkjet has been developed. The advantages of this method are among others:

- its interest for low cost gas sensor application;

- the absence of cracks in films;

- the simplicity of synthesis: only two ingredients (nanoparticles of zinc oxide and ethylene glycol);

- the simplicity of deposition;

- a good control of the dispersal of particles over the substrate.

This paper describes the process in the study of the deposition profiles of $\mathrm{ZnO}$ nanoparticles fabricated by Sigma Aldrich (10\% weight) in suspension in ethylene glycol (EG) solution and a mixture of $2.5 \% \mathrm{w} / \mathrm{w}$ and $5 \% \mathrm{w} / \mathrm{w}$ diethylene glycol (DEG), at three temperatures: $65^{\circ} \mathrm{C}, 105^{\circ} \mathrm{C}$ and $110^{\circ} \mathrm{C}$. Then, a first study of the $\mathrm{ZnO}$ layer sensitivity under methane $\left(\mathrm{CH}_{4}\right)$ has been achieved. To finish, tests under polluting gases $\mathrm{C}_{2} \mathrm{H}_{4} \mathrm{O} / \mathrm{NO}_{2}$ have been analyzed.

\section{Materials and Methods}

\section{The inkjet machine}

The inkjet machine used is a "drop on demand" type, manufactured by Altatech. The principle of this machine is described in Figure 1.

This machine consists of a system of wafer automatic transfer with an automatic alignment with a precision of \pm 4 microns. The chuck can be warmed until $150^{\circ} \mathrm{C}$ and accept wafers up to 6 inches of diameter. The heads of mono inkjet buzzards are made by the Microphone Fab Company. The temperature of heads can be carried until $120^{\circ} \mathrm{C}$ to decrease the ink viscosity. 
The movement of the chuck has also a $\pm 4 \mu \mathrm{m}$ precision. A display camera allows to center the jet on a target and to make an observation after jetting. A tromboscopic system allows to visualize the drops formation and to measure their ejected speed. The own setup is driven by a computer: chuck moving and jetting parameters to control drop formation and the printing modes (drop on position, print-on fly). The density meter Jobin Yvon Horiba LA-950V2 of Horiba Jobin-Yvon is a granulometer with diffraction laser. It allows determining the size and the distribution of particles in suspension in a liquid. The range of measure is between $0.01 \mu \mathrm{m}$ and $3000 \mu \mathrm{m}$. This device allows the analysis of the quality of the suspensions. The ultrasonic probe (Biblioblock Vibra Cell) is used for the dispersal of nanoparticles in the ethylene glycol. A maximal power of $500 \mathrm{~W}$ is available with a function of pulsed power which allows, by rest of time, to avoid a too important rise of temperature.

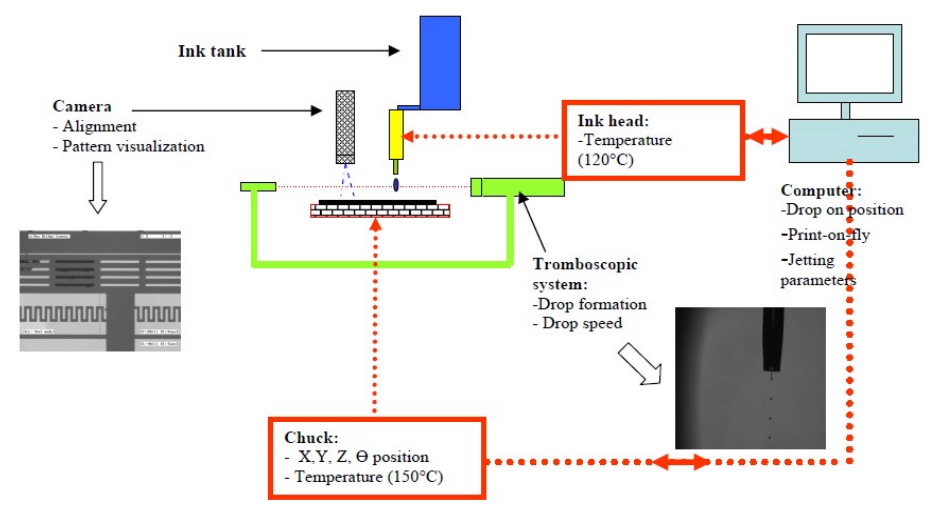

Figure 1. Principle of Altadrop inkjet machine.

\section{Generalities on inkjet deposition technique}

There are different approaches to write lines or to draw structures in microtechnology. The method "print-on fly" which is the one which is used in printing office in which, the substrate and the head move in a continuous way; drops are ejected according to drawing generation parameters. The writing is very fast and all the drawn designs will have the same parameters of deposit. This method is thus adapted to an already well optimized process. 
The second method is "the drop on position". In that case, each design is treated in an individual way, with its own parameters. By observing the impact of a drop which arrives on a surface, it can be showed that complex phenomena take place and made the object of numerous studies [19, 20]. The mechanism of deposit of a drop can be separated in two stages:

- a stage in which the kinetic energy is dissipated;

- a stage in which the drop will have to spread out on the surface and the diameter of which will depend on energy interactions between the surface and the ink.

In these two stages, it is often necessary to add a third one which is the evaporation of the solvent. In the simplest case, the width of a line is given by the formula (1) [20]:

$$
W=(\theta d 3 / 6 p) /(\theta / 4 \sin 2 \theta-\cos \theta / 4 \sin \theta)^{1 / 2},
$$

where $W$ represents the width of the line, $\theta$ the contact angle that makes the drop with the substrate, $p$ the distance between 2 drops and $d$ the diameter of the drop.

\section{ZnO ink synthesis and deposit on microhotplate}

The zinc oxide used for this experiment is a commercial material consisting of $\mathrm{ZnO}$ nanoparticles with diameter size between 50 and $70 \mathrm{~nm}$.

Ink preparation and surface treatment is realized in LAAS Laboratory with also commercialized products with extreme purity as ethylene glycol, octadecyltrichlorosilane and bi-ethylene glycol.

To synthetize the ink, a $10 \%$ concentration in weight of $\mathrm{ZnO}$ nanoparticles is put in suspension in the ethylene glycol without any additive which could contaminate the sensing layer of the sensor. Then the mixture is shaken by hanging ultrasounds during 30 minutes by means of the probe.

This ink is stable as after several weeks, any precipitate which would show sedimentation in time is observed. This result was also confirmed by a Horiba granulometer. This stable behavior is very interesting (in comparison 
with the $\mathrm{SnO}_{2}$ nanoparticle colloid), since the ink is very simple to synthesize unlike most deposits of inkjet sensitive material that can be found in the literature [18].

Before the $\mathrm{ZnO}$ material deposit, a treatment of the wafer is necessary. It consists in a functionalization of sensitive layer surface. After stewing the oxidized wafer at $150^{\circ} \mathrm{C}$ during one hour, $2.7 \mu \mathrm{m}$ of $\mathrm{AZ} 1529$ resin are deposited by spin coating; followed-up by a pre-baking at $105^{\circ} \mathrm{C}$ during 1 minute. After exposition to UV light achieved to design sensitive layer surface, the development is made in the AZ developer during 30 seconds followed by cleaning and drying under nitrogen. A hard bake is made at $115^{\circ} \mathrm{C}$ during 1 minute. The wafer is then immersed in a solution of OTS ( $2 \%$ in volume) in the hanging trichloroethylene during 2 minutes. This operation is followed by successive rinsing in trichloroethylene, acetone and deionized water. A drying in the nitrogen flow is followed by a dehydration baking 10 minutes in furnace at $120^{\circ} \mathrm{C}$. The quality of the surface functionalization is checked by contact angle measurements. A contact angle of $107^{\circ}$ is obtained on the treated region by OTS with a drop of water while the untreated region gives angles from 25 to $60^{\circ}$.

The ink is then deposited on a designed platform which is a generic structure that can adapt to different sensitive layer deposition techniques, such as sputtering or inkjet printing. This platform has the capacity to climb up to $550^{\circ} \mathrm{C}$, for a corresponding power consumption of only $60 \mathrm{~mW}$. The heating resistance is necessary to activate the sensitive element $\mathrm{ZnO}$.

Principal jetting parameters are:

- dot-spacings: $20 \mu \mathrm{m}$;

- droplet diameters: $60 \mu \mathrm{m}$.

The following figures show this sensor: 


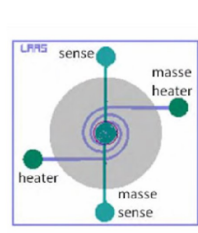

(a)

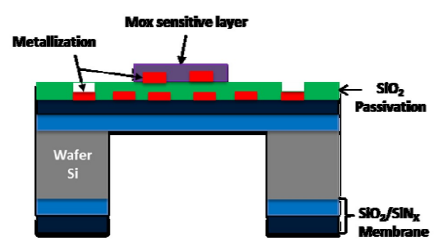

(b)

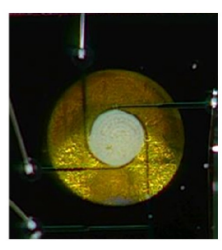

(c)

Figure 2. $\mathrm{ZnO}$ sensing layer deposit on microhotplates.

\section{Tests under gases}

To test the gas sensors under gases, a dilution bench (Figure 3) developed at LAAS-CNRS [21] is used. This bench in which all the parameters are known and controlled allows to precisely control the gaseous environment in which the sensor will be placed (total flow, relative humidity, concentration of each gas), also the temperature of the heating platform and/or the enclosure.

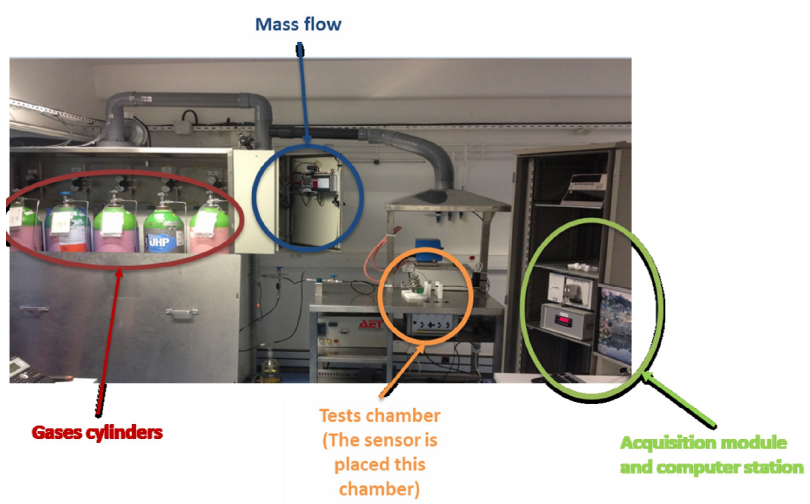

Figure 3. Dilution bench of LAAS-CNRS.

To carry out our study, hygrometry was set at $30 \%$, the total flow at $200 \mathrm{cc} / \mathrm{min}$, and the measurement current for the sensor was set at $10 \mathrm{nA}$.

\section{Results and Discussions}

First work achieved is to evaluate the optical aspect of printed lines obtained with $0 \%, 2.5 \%$ and $5 \%$ DEG inks at $65^{\circ} \mathrm{C}, 105^{\circ} \mathrm{C}$ and $110^{\circ} \mathrm{C}$ substrate temperatures. 

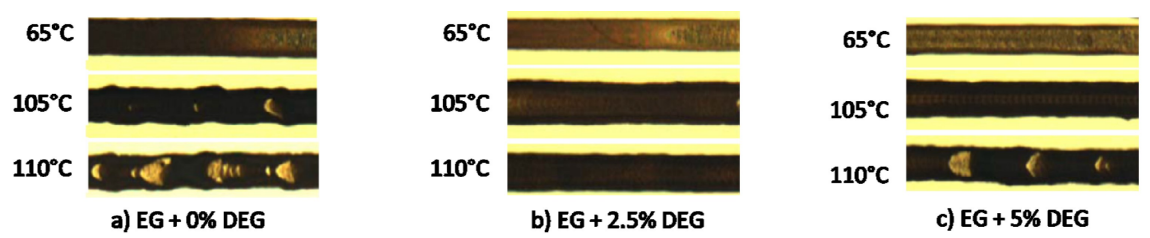

Figure 4. Optical aspect of printed lines obtained with: (a) $0 \%$, (b) $2.5 \%$ and (c) $5 \%$ DEG inks at three temperatures.

At first sight in Figure 4, better results are obtained by the ink with 2.5\% DEG for the three temperatures with a smoother print line. Bad aspects are obtained at $110^{\circ} \mathrm{C}$ for inks containing $0 \%$ and $5 \%$ DEG with particles agglomerates.

Unfortunately, a bubble can be seen at the line-start (Figure 5). This phenomenon described by Duineveld [22] decreases here greatly at $105^{\circ} \mathrm{C}$ as illustrated in Figure 5(b). Better line width is obtained at $65^{\circ} \mathrm{C}$ for $2.5 \%$ DEG ink, but the thickness is lower, due to the $\mathrm{ZnO}$ transfer towards the bubble.
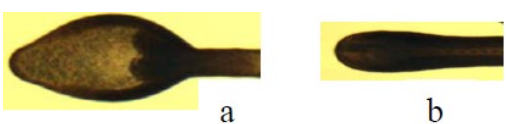

Figure 5. Optical images in line-start for $2.5 \%$ DEG at (a) $65^{\circ} \mathrm{C}$ and (b) $105^{\circ} \mathrm{C}$.

$\mathrm{ZnO}$ profiles in Figure 6 show the profiles distribution of printed lines obtained with $0 \%, 2.5 \%$ and $5 \%$ DEG inks at $65^{\circ} \mathrm{C}, 105^{\circ} \mathrm{C}$ and $110^{\circ} \mathrm{C}$ substrate temperatures. The profiles in Figure 4 confirm these results and the ink containing $2.5 \%$ DEG gives more homogeneous profiles.

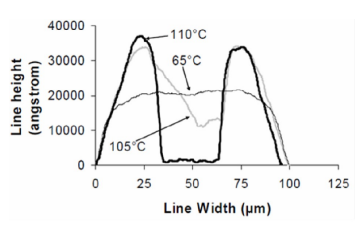

a) $0 \%$ DEG

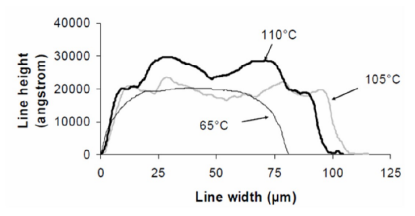

b) $2.5 \%$ DEG

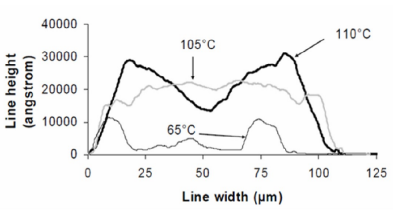

c) $5 \%$ DEG

Figure 6. $\mathrm{ZnO}$ profiles distribution for (a) $0 \%$, (b) $2.5 \%$ and (c) $5 \%$ DEG inks at three temperatures. 
Considering the good results for the three temperatures obtained with ink with $2.5 \%$ DEG deposited at $65^{\circ} \mathrm{C}$, it is used to study the behavior of $\mathrm{ZnO}$ films under gazes according to temperature.

Tests under gases are achieved after a stabilization period of 2 hours in humid air.

In Figure 7, the curve of $\mathrm{ZnO}$ sensor response to $\mathrm{CH}_{4}$ at different temperatures is presented. A maximum response is obtained at $225^{\circ} \mathrm{C}$ for $\mathrm{CH}_{4}$ detection. A comparison with $\mathrm{ZnO}$ ink synthetized with $0 \%$ DEG and deposited at $65^{\circ} \mathrm{C}$ shows the performance of ink with $2.5 \%$ DEG deposited at $65^{\circ} \mathrm{C}$.

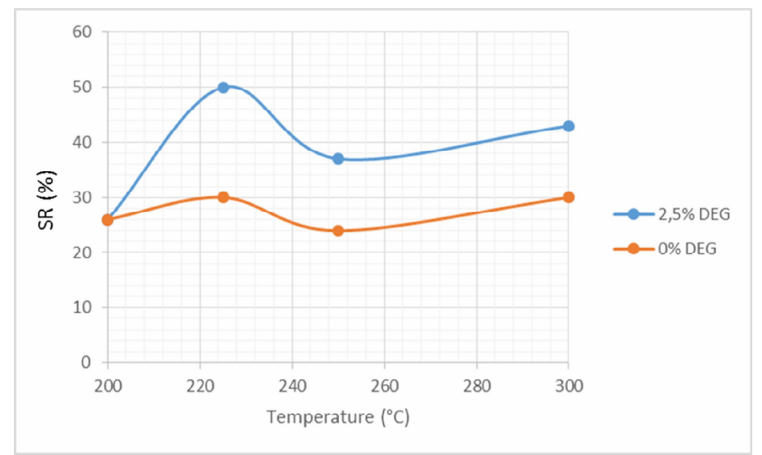

Figure 7. $\mathrm{ZnO}$ gas sensor response with $0 \%$ and $2.5 \%$ DEG inks compositions, versus temperatures for $\mathrm{CH}_{4}$ detection.

The sensor response is defined by the relation (2):

$$
S R(\%)=100 *\left(R_{\text {gas }}-R_{\text {air }}\right) / R_{\text {air }} .
$$

A second test using a dynamic power profile is achieved. The profile consists of two levels. A high level at $50 \mathrm{~mW}$ corresponding to a temperature around $450^{\circ} \mathrm{C}$ and a low level of power at $30 \mathrm{~mW}$ corresponding to a temperature of $250^{\circ} \mathrm{C}$. The duration of each step is 30 seconds.

For this test, a mixture of gaseous pollutants composed of acetaldehyde $\mathrm{C}_{2} \mathrm{H}_{4} \mathrm{O}(2 \mathrm{ppm})$ and nitrogen dioxide $\mathrm{NO}_{2}(0.2 \mathrm{ppm})$ is used. The response of the sensor under several identical injections of the same mixture of gas is 
analyzed. Between two successive injections of gas, moist air is injected for $1 / 2$ hour in order to stabilize the sensor.

Figure 8 presents a comparison of the $\mathrm{ZnO}$ sensor response according to the dynamic power profile to three injections of a mixture $\mathrm{C}_{2} \mathrm{H}_{4} \mathrm{O} / \mathrm{NO}_{2}$. The responses at $50 \mathrm{~mW}$ are very high (between 200 and $350 \%$ ) while those at $30 \mathrm{~mW}$ are low $(20 \%)$. Even if the responses seem stable over the whole dynamic profile, those at $50 \mathrm{~mW}$ present greater variability than responses at $30 \mathrm{~mW}$.

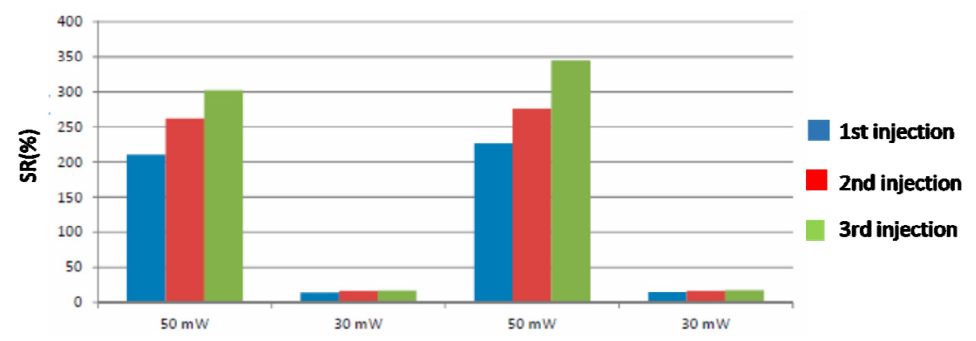

Figure 8. Diagram of a response versus power of a $\mathrm{ZnO}$ sensor during 3 injections cycle under $\mathrm{C}_{2} \mathrm{H}_{4} \mathrm{O} / \mathrm{NO}_{2}$.

\section{Conclusion}

This paper presents a new way of manufacturing efficient low-cost gas sensors based on metal oxide deposited by inkjet printing method. In our case, we presented the inkjet process, the material used ( $\mathrm{ZnO}$ in ethylene glycol) and the parameters that give the best homogeneity and reproducibility.

As per the results obtained, EG is a good support for the realization of inks containing nanoparticles in suspension. Better profiles were obtained by the addition of $2.5 \%$ DEG with a better homogeneity of the $\mathrm{ZnO}$ layer.

Results under gases show an improvement on the response of sensor for $\mathrm{CH}_{4}$ and stable responses with $\mathrm{C}_{2} \mathrm{H}_{4} \mathrm{O} / \mathrm{NO}_{2}$.

This work indicated that the inkjet printing method is promising for the preparation of sensing layers for gas sensors. 


\section{Acknowledgement}

The authors express their gratitude to LAAS-CNRS for help given for the realization of this work.

\section{References}

[1] A. Dey, Semiconductor metal oxide gas sensors: a review, Materials Science and Engineering: B 229 (2018), 206-217.

[2] E. Comini, Metal oxide nanowire chemical sensors: innovation and quality of life, Materials Today 19(10) (2016), 559-567.

[3] X. Liu, Y.-Z. Long, L. Liao, X. Duan and Z. Fan, Large-scale integration of semiconductor nanowires for high-performance flexible electronics, ACS Nano 6(3) (2012), 1888-1900.

[4] S. Phanichphant, Semiconductor metal oxides as hydrogen gas sensors, Procedia Engineering 6(3) (2012), 795-802.

[5] N. Yamazoe, Toward innovation of gas sensor technology, Sensors and Actuators B 108 (2005), 2-4.

[6] N. Barsan and U. Weimer, Conduction model of metal oxide gas sensors, J. Electroceram. 7 (2001), 143-167.

[7] X.-J. Huang and Y.-K. Choi, Chemical sensors based on nanostructured nanomaterials, Sensors and Actuators B 122 (2007), 659-671.

[8] Y. Deng, Semiconducting metal oxides: composition and sensing performance, Semiconducting Metal Oxides for Gas Sensing, Springer, 2019.

[9] C. N. Xu, J. Tamaki, N. Miura and N. Yamazoe, Grain size effects on gas sensitivity of porous $\mathrm{SnO}_{2}$-based elements, Sensors and Actuators B: Chemical 3(2) (1991), 147-155.

[10] Y. Deng, Morphology and sensing performance, Semiconducting Metal Oxides for Gas Sensing, Springer, 2019.

[11] M. Pashchanka, A. Gurlo, R. M. Prasad, N. Nicoloso, R. Riedel and J. J. Schneider, Inkjet printed $\operatorname{In}_{2} \mathrm{O}_{3}$ and $\operatorname{In}_{2} \mathrm{O}_{3} / C N T$ hybrid microstructures for future gas sensing application, IMCS 2012 - The 14th International Meeting on Chemical Sensors, 2012. 
[12] Robert D. Deegan, Olgica Bakajin, Todd F. Dupont, Greg Huber, Sidney R. Nagel and Thomas A. Witten, Contact line deposits in an evaporating drop, Phys. Rev. E 62 (2000), 756-765.

[13] Z. Tang, P. C. H. Chan, R. K. Sharma, G. Yan, I.-M. Hsing and J. K. O. Sin, Investigation and control of microcracks in tin oxide gas sensing thin-films, Sensors and Actuators B: Chemical 79 (2001), 39-47.

[14] J.-H. Lee, Gas sensors using hierarchical and hollow oxide nanostructures: overview, Sensors and Actuators B 140(1) (2009), 319-336.

[15] E. Gyoergy, G. Socol, I. N. Mihailescu, J. Santiso, C. Ducu and S. Ciuca, Pulsed laser deposited zinc oxide thin films for optical gas sensor applications, Proceedings of SPIE - The International Society for Optical Engineering, 2005.

[16] T. M. Barnes, J. Leaf, C. Fry and C. A. Wolden, Room temperature chemical vapor deposition of $c$-axis ZnO, J. Crystal Growth 274 (2005), 412-417.

[17] C. Matei Ghimbeu, J. Schoonman, M. Lumbreras and M. Siada, Electrostatic spray deposited zinc oxide films for gas sensors applications, Applied Surface Science 253(18) (2007), 7483-7489.

[18] W. Shen, Y. Zaho and C. Zhang, The preparation of ZnO gas-sensing thin film by ink-jet printing method, Thin Solid Films 483 (2005), 382-387.

[19] S. Schiaffino and A. Sonin, Formation and stability of liquid and molten beads on a solid surface, J. Fluid Mech. 343 (1997), 95-110.

[20] J. Stringer and B. Derby, Limits to feature size and resolution in ink jet printing, J. European Ceramic Society 29 (2009), 913-918.

[21] N. Dufour, Conception et réalisation d'un multicpateur de gaz intégré à base de plateforme chauffante sur silicium et de couches sensibles à oxydes métalliques pour le contrôle de la qualité de l'air habitacle, Thèse de l'Université Paul Sabatier de Toulouse III, 2013.

[22] P. C. Duineveld, The stability of ink-jet printed lines of liquid with zero receding contact angle on a homogeneous substrate, J. Fluid Mech. 477 (2003), 175-200. 